\title{
Region-Scaled Soil Erosion Assessment using USLE and WEPP in Korea
}

\author{
Min-Kyeong Kim ${ }^{1)}$, Kang-Ho Jung ${ }^{1)}$, Sun-Gang Yun ${ }^{1)}$, and Chul-Soo Kim ${ }^{2) \star}$ \\ ${ }^{1)}$ Department of Agricultural Environment, National Academy of Agricultural Science, RDA, Suwon 441-707, Korea \\ ${ }^{2)}$ Department of Civil Engineering, Kyungbuk National University, Sangju 742-711, Korea \\ (Received November 11, 2008, Accepted December 23, 2008)
}

\begin{abstract}
During the summer season, more than half of the annual precipitation in Korea occurs during the summer season due to the geographical location in the Asian monsoon belt. So, this causes severe soil erosion from croplands, which is directly linked to the deterioration of crop/land productivity and surface water quality. Therefore, much attention has been given to develop accurate estimation tools of soil erosion. The aim of this study is to assess the performance of using the empirical Universal Soil Loss Equation (USLE) and the physical-based model of the Water Erosion Prediction Project (WEPP) to quantify eroded amount of soil from agricultural fields. Input data files, including climate, soil, slope, and cropping management, were modified to fit into Korean conditions. Chuncheon (forest) and Jeonju (level-plain) were selected as two Korean cities with different topographic characteristics for model analysis. The results of this current study indicated that better soil erosion prediction can be achieved using the WEPP model since it has better power to illustrate a higher degree of spatial variability than USLE in topography, precipitation, soils, and crop management practices. These present findings are expected to contribute to the development of the environmental assessment program as well as the conservation of the agricultural environment in Korea.
\end{abstract}

Key Words: Soil erosion, Universal Soil Loss Equation (USLE), Water Erosion Prediction Project (WEPP)

\section{INTRODUCTION}

Soil erosion causes a serious problem that stems from a combination of environmental impacts ${ }^{1)}$ and crop productivity loss, ${ }^{2,3)}$ which makes the understanding of the erosion process important to guarantee food security $^{4)}$ and environmental safety. ${ }^{5}$ Erosion is considered to have the greatest impact among surface hydrologic processes and in the future, it may be exacerbated in the future in many parts of the world because of climate change towards a more vigorous hydrologic cycle. $\left.{ }^{6}\right)$ Therefore, it has a great deal of importance in optimizing policies for management of water resources. ${ }^{7}$

In recent decades, empirically, conceptually, or physically

"Corresponding author:

Tel: +82-54-530-1259 Fax: +82-54-530-1419

E-mail: csk@knu.ac.kr based models have been built in order to represent and quantify the processes of detachment, transport, and deposition of eroded soil, with the aim of implementing assessment tools for educational, planning, and legislative purposes. ${ }^{8)}$ Calibration of models is different since the phenomena are complex and depend on many parameters, especially because filed data are usually not sufficient and relate to small spatial and temporal contexts.

Empirical models are still used because of their simple structure and ease of application, but they cannot describe nor simulate the erosion process as a set of physical phenomena because they are based on coefficients computed or calibrated on the basis of measurement and/or observation. Contrary to empirical models, physically based models simulate the individual components of the entire erosion process by solving the corresponding equations and so it is argued that 
they tend to have a wider range of applicability. Generally, models are also better in terms of their capability to assess both the spatial and temporal variability of the natural erosion processes.

The Universal Soil Loss Equation (USLE) is the most widely used empirical erosion model. ${ }^{9)}$ It estimates soil erosion from an area simply as the product of empirical coefficients, which must therefore be accurately evaluated. While the USLE was used extensively to predict long-term average annual soil loss, it was a mature technology that could not easily be expanded to meet the ever increasing needs of conservationists and environmental managers, e.g., a limitation to apply only detaching regions of a hillslope and to estimate sediment deposition or sediment delivery from fields to off-site channels or streams. No capabilities to estimate runoff, spatial locations of soil loss on a hillslope profile or within a small watershed, channel erosion, effects of impoundments, recurrence probabilities of erosion events, or watershed sediment yields. ${ }^{10)}$

The Water Erosion Prediction Project (WEPP) was developed to address all of these needs which USLE cannot deal with, and to serve as a replacement for empirically based erosion prediction technologies like USLE. WEPP is one of the well-known physically based model that predicts soil loss and deposition using a spatially and temporally distributed approach. ${ }^{11,12,13)}$

Most current erosion and runoff modeling are typically limited in spatial and temporal extent due to the use of field measurements for prediction data and/or use of long-term average prediction data to estimate probable soil erosion rates. Long-term average are the basis for estimating rainfall erosivity characteristics used in empirically based soil erosion models such as the USLE ${ }^{9)}$ and it derivatives. These estimates may be suitable for planning management and conservation practices to meet government compliance requirements. However, the impacts of highly variable and extreme precipitation events cannot be estimated with long-term averages. The extreme precipitation causes the majority of damage in most locations and situations. ${ }^{14)}$ Furthermore, the result of soil loss using the USLE used to apply with political practice in Korea. However, it is more necessary for opportunities to target degradation require location specific information.
Therefore, the objectives of this study were: 1) to adopt and modify WEPP model to fit into Korea conditions, 2) to apply WEPP and USLE to agricultural fields in Chuncheon and Jeonju, and 3) to evaluate their performance to predict soil erosion due to precipitation and runoff.

\section{MATERIALS AND METHODS}

\section{Description of the study sites}

Chuncheon is located in northeastern Korea ( $\mathrm{N}$ $37^{\circ} 54^{\prime}$ and E $127^{\circ} 44^{\prime}$ ) covering an agricultural area of $124.7 \mathrm{~km}^{2}$, while Jeonju with an agricultural area of $50.0 \mathrm{~km}^{2}$ is located in southwestern Korea ( $\mathrm{N} \mathrm{35}^{\circ} 49^{\prime}$ and $\mathrm{E} 127^{\circ} 09^{\prime}$ ) (Fig. 1). The topography of both sites varies from steep forests to nearly level plains. Chuncheon is at a higher altitude $(76.8 \mathrm{~m}$, base MSL) and has more forests than Jeonju (53.5 m, base MSL). For its agricultural land, Chuncheon consists of 33.6\% paddy fields and $57.2 \%$ uplands, while Jeonju has $32.9 \%$ paddy fields and $11.6 \%$ uplands.

The drainage areas of the study areas have 4,427 ha with 22 hillslopes in Chuncheon and 654 ha with 10 hillslopes in Jeonju while the longitudinal slopes are averages of 11.0 and $9.0 \%$, respectively (Table 1). At Chuncheon, the soil is a sandy loam with an average of $17.0 \%$ clay and $2.0 \%$ organic matter. While, at Jeonju, the soil is a silty loam with $13.8 \%$ clay and $2.0 \%$ organic matter. For soil type, Chuncheon have 15 kinds of soil series such as Anryong, Asan, Baegsan, Deogcheon, Gupyeong, Hwangryong, Ihyeon, Neogog, Pungcheon, Sangju, Seogto, Seongsan, Suam, Yeongog, and Yesan. In addition, Jeonju has 7 kinds of soil series with Deogcheon, Ihyeon, Pungcheon,

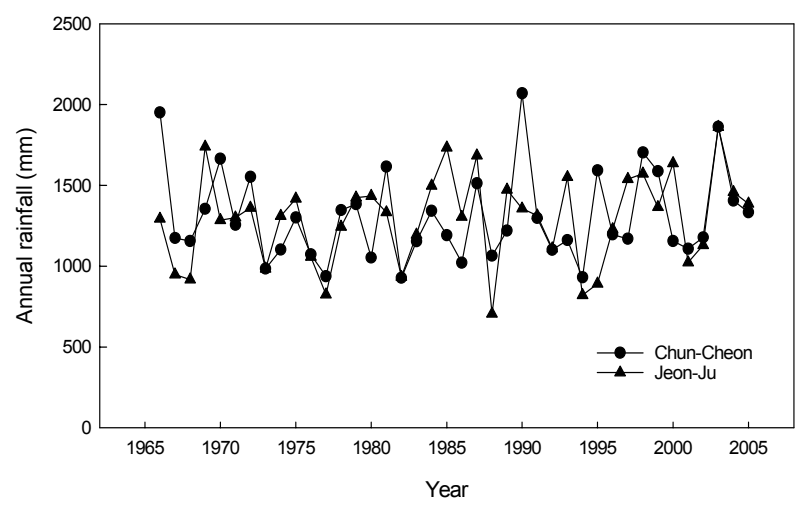

Fig. 1. Time series of rainfall for Chuncheon and Jeonju constructed from daily observations from 1966 to 2005 . 
Table 1. Description of the soil and crop management used in this study

\begin{tabular}{ccccc}
\hline Location & Total area (ha) & Average slope $(\%)$ & Soil texture $^{1)}$ & Crop / Management $^{1)}$ \\
\hline Chuncheon & 4,427 & 11.0 & Sandy loam & Corn, soybean / conservation tillage \\
Jeonju & 654 & 9.0 & Silty loam & Corn, soybean / conservation tillage \\
\hline
\end{tabular}

1) Based on county soil surveys from National Institute of Agricultural Science \& Technology of Korea, soils on which crops are successfully grown.

Seogto, Suam, Yeongog, and Yesan. However, the same crop with corn and soybean are cultivated at both sites with the same conservation tillage.

\section{Model implementation I: Universal Soil Loss Equation (USLE)}

The USLE model is an empirical model that was originally developed in 1954 from over 10,000 plot years of data from both natural rainfall and rainfall simulator plots data. ${ }^{15)}$ This allows one to estimate average annual soil loss for given natural and anthropogenic condition. It is a simple equation of the form:

$$
A=R \cdot K \cdot L \cdot S \cdot C \cdot P
$$

Where, $A$ is the computed soil erosion rate per unit basin area commonly expressed in ton $\mathrm{ha}^{-1} \mathrm{yr}^{-1} . R$ is a rainfall erosivity factor calculated by the summation of the erosion index over the period of evaluation (30-min maximum intensity). $K$ is a soil erodibility factor, which is expressed as the average soil loss per unit of the $R$ factor. $L$ is an index of slope length, expressed as the ratio of the expected soil loss to that observed for a field of $22.6-\mathrm{m}$ in length. $S$ is a slope steepness index, the ratio of the expected soil loss to that observed for a field of specified slope ( $9 \%$ ). $C$ is a dimensionless cover management factor that is measured as the ratio of soil loss from land cropped under varying cover management conditions. $P$ is a dimensionless conservation practice factor that is expressed as the ratio of soil loss with a specific support practice to the corresponding loss with up- and downslope culture.

The average $R$ factors of the study sites were calculated using the inverse distance weight method based on $1 \mathrm{~km}$ spatial unit TM coordinates from $\sum \mathrm{EI}_{30}$ of Park. ${ }^{16)}$ Where E was the total kinetic energy of rainfall and $\mathrm{I}_{30}$ was the 30-minute maximum rainfall intensity. The former was analyzed using the rainfall data in 69 observation stations of Korea Meteorological
Administration (KMA) from 1969 to 1978 and the latter was done in 53 sites from 1973 to 1996 to calculate $\sum \mathrm{EI}_{30}$ is the $\mathrm{MJ} \mathrm{mm} \mathrm{ha}^{-1} \mathrm{yr}^{-1} \mathrm{hr}^{-1}$. The $\mathrm{K}$ factors were calculated with the equation modified by Box $^{17)}$ and this $\mathrm{K}$ factor was originally developed by Wischmeier and Smith in 1978. For LS factor, the median value (\%) of slope grade of soil phase was converted into slope angle and slope length was determined as the representative value with land use type using soil map $(1: 25,000)$. The evaluate the $C$ factor with covered crop, the experimental results from 1977 to 2001 conducted by the Soil Conservation Laboratory in the National Academy of Agricultural Science (NAAS) on field lysimeter plots were collected. The $\mathrm{C}$ factor was calculated and it was applied on a national scale to yield estimation. The average $\mathrm{C}$ factor for a province was estimated by average over cultivated area and $C$ factor of major crops. The $\mathrm{P}$ factors for croplands were determined using the results of NAAS from 1976 to 1999 by lysimeter studies.

\section{Model implementation II: Water Erosion Prediction Project (WEPP) model}

The WEPP model for estimating soil erosion and water runoff has been a good predictor of soil erosion at time scales ranging from individual events to long-term average annual. ${ }^{13,18)}$ The model is composed of several components taking into account climate, hydrology and water balance, plant growth with residue decomposition and agricultural practices, in addition to soil composition and consolidation. WEPP is a physical-based, continuous daily simulation computer software program for estimating sheet and rill erosion by water. Many examples of WEPP application could be found in the scientific literature, including: the influence of different soil uses on model results (Lindstrom et al., 1999); the calibration of some variable sin situations different than those initially provided with the model, such as transport 
capacity in rill shallow water $^{19)}$ and erodibility parameters in rangeland; ${ }^{18)}$ and the calibration of parameters regarding infiltration and runoff processes. ${ }^{19)}$

Runoff and soil loss resulting from individual storm events are calculated and accumulated, and also the outputs by day, month, and year over the entire simulation period are available. Both temporal and spatial soil detachment and/or deposition are predicted. $^{13)}$

The Hillslope version (v2006.5) of the WEPP model $^{13)}$ with its Windows-based Graphical User Interface was used in this study. In order to run the model, it was necessary to prepare four different input files for climate, soil, slope, and crop management. The Meteorological Information Web Service System-Disaster Prevention (MISS-DP) of KMA was able to provide the needed daily information such as precipitation, temperature, solar radiation, and wind data required to drive the hydrology and plant growth components of the WEPP model. The NAAS of Korea is the source of publicly available soil, slope, and cropping management input data required for this study. ${ }^{20)}$ A summary of the two selected models, USLE and WEPP, is listed in Table 2.

\section{RESULTS AND DISCUSSION}

\section{Patterns of annual precipitation}

Baseline climate was determined using measured daily precipitation, maximum temperature, and minimum temperature at the Chuncheon and Jeonju weather stations between 1966 and 2005. Mean annual precipitation in Chuncheon and Jeonju was 1,305 and 1,291 $\mathrm{mm}$ from 1966 to 2005, respectively. The annual precipitation at Chuncheon was similar to Jeonju except for a few years (Fig. 1).

The change of precipitation in winter (October-March) on a monthly basis was uniform for both sites (Fig. 2 ), and the mean precipitation in Jeonju was slightly higher than that in Chuncheon. However, the precipitation change was not uniform in the summer months (April-September), while in July and August, the mean precipitation at Chuncheon was much higher than that in Jeonju in July and August. The overall pattern is quite similar to that of monthly total precipitation for the sites. In fact, the overall increase of summer precipitation in Chuncheon and Jeonju can be attributed to an increase in precipitation amount on wet days and an increase in the number of wet days on average during the summer season. However, the average precipitation on wet days for the winter season in Jeonju was a little higher than that in Chuncheon. This indicates a higher soil loss potential for hillslopes in Jeonju during the winter season.

\section{Comparison of USLE and WEPP average annual soil erosion predictions}

Soil loss estimates were computed for each hillslopes in Chuncheon and Jeonju for comparisons of the USLE and WEPP on average annual soil erosion. Table 3 shows a comparison of average annual soil erosion in Chuncheon and Jeonju as predicted by the USLE with WEPP. The average annual soil

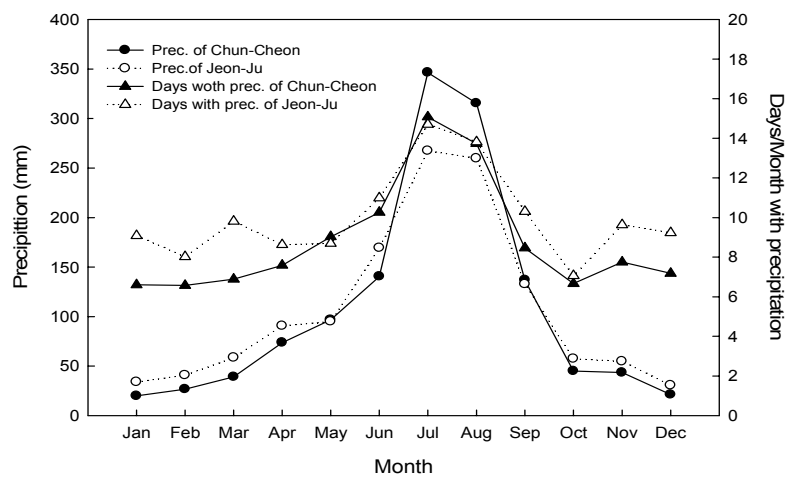

Fig. 2. Mean monthly precipitation, monthly means of precipitation, and number of days with precipitation in Chuncheon and Jeonju for 1966-2005.

Table 2. Main properties of both erosion prediction models used in this study

\begin{tabular}{ccccccc}
\hline Model & Model type & $\begin{array}{c}\text { Scale of } \\
\text { application }\end{array}$ & $\begin{array}{c}\text { Hydrology } \\
\text { processes }\end{array}$ & $\begin{array}{c}\text { Erosion } \\
\text { processes }\end{array}$ & $\begin{array}{c}\text { Level of data } \\
\text { input }\end{array}$ & $\begin{array}{c}\text { Use in Korean } \\
\text { institute }\end{array}$ \\
\hline USLE & Empirical & Hillslope & $\begin{array}{c}\text { Infiltration } \\
\text { excess } \\
\text { (Hortonian) }\end{array}$ & Sheet and rill & Low & $\begin{array}{c}\text { Basis for erosion } \\
\text { assessment from 1993 } \\
\text { to } 1997\end{array}$ \\
WEPP & Physical-based & $\begin{array}{c}\text { Hillslope to } \\
\text { small catchment }\end{array}$ & $\begin{array}{c}\text { Infiltration } \\
\text { excess }\end{array}$ & Sheet and rill & High & Not used \\
\hline
\end{tabular}


Table 3. Average annual soil erosion in Chuncheon and Jeonju as given in the USLE with WEPP predicted average annual soil erosion

\begin{tabular}{ccc}
\hline Location & $\begin{array}{c}\text { Mean soil loss by USLE } \\
\left(\text { ton } \mathrm{ha}^{-1} \mathrm{yr}^{-1}\right)\end{array}$ & $\begin{array}{c}\text { Mean soil loss by WEPP } \\
\left(\text { ton } \mathrm{ha}^{-1} \mathrm{yr}^{-1}\right)\end{array}$ \\
\hline Chuncheon & 24.8 & 16.5 \\
& $(1.8 \sim 63.1)$ & $(2.0 \sim 35.3)$ \\
Jeonju & 23.5 & 23.4 \\
$(2.4 \sim 59.1)$ & $(5.1 \sim 58.6)$ \\
\hline
\end{tabular}

erosion predicted by the USLE over all hillslopes in Chuncheon was 24.8 ton $\mathrm{ha}^{-1} \mathrm{yr}^{-1}$ (ranging from 1.8 to 63.1 ton $\mathrm{ha}^{-1} \mathrm{yr}^{-1}$ ) while WEPP predicted average annual soil erosion was 16.5 ton $\mathrm{ha}^{-1} \mathrm{yr}^{-1}$ (ranging from 2.0 to 35.3 ton $\mathrm{ha}^{-1} \mathrm{yr}^{-1}$ ). In Jeonju, the average annual soil erosion predicted by the USLE was 23.5 ton $\mathrm{ha}^{-1} \mathrm{yr}^{-1}$ (ranging from 2.4 to 59.1 ton $\mathrm{ha}^{-1} \mathrm{yr}^{-1}$ ), while WEPP predicted average annual soil erosion was 23.4 ton $\mathrm{ha}^{-1} \mathrm{yr}^{-1}$ (ranging from 5.1 to 58.6 ton $\left.\mathrm{ha}^{-1} \mathrm{yr}^{-1}\right)$.

Figure 3 shows a comparison of USLE soil erosion estimates and WEPP predicted average annual soil erosion over all study sites in Chuncheon and Jeonju. There was a little variability between the estimates in Chuncheon $\left(r^{2}=0.6841\right)$ and Jeonju $\left(r^{2}=0.8891\right)$. There are a number of factors that could cause these differences. WEPP uses a much different prediction approach, and hence uses far different characteristics of the soil and slope for estimating soil erosion. Especially, the range of management systems and the selection method of management systems while based on the USLE, would not always produce the same management system used in the USLE, and hence would contribute to the variability shown in Fig. 3.

\section{CONCLUSIONS}

Accurate estimation of soil erosion due to water is very significant in several environmental contexts, such as the assessment of potential soil loss from cultivated lands and the evaluation of the loss of crop productivity and soil quality. However, reliable prediction of the quantity and rate of water-induced erosion from land surface into streams and rivers is difficult, expensive and time consuming, particularly in Korea because of very complex land-use and cover types exist within small scale of lands. On top of the wide usage of USLE, WEPP model has been extensively used recently in Korea as a very powerful tool to predict estimation of soil loss. However, the WEPP
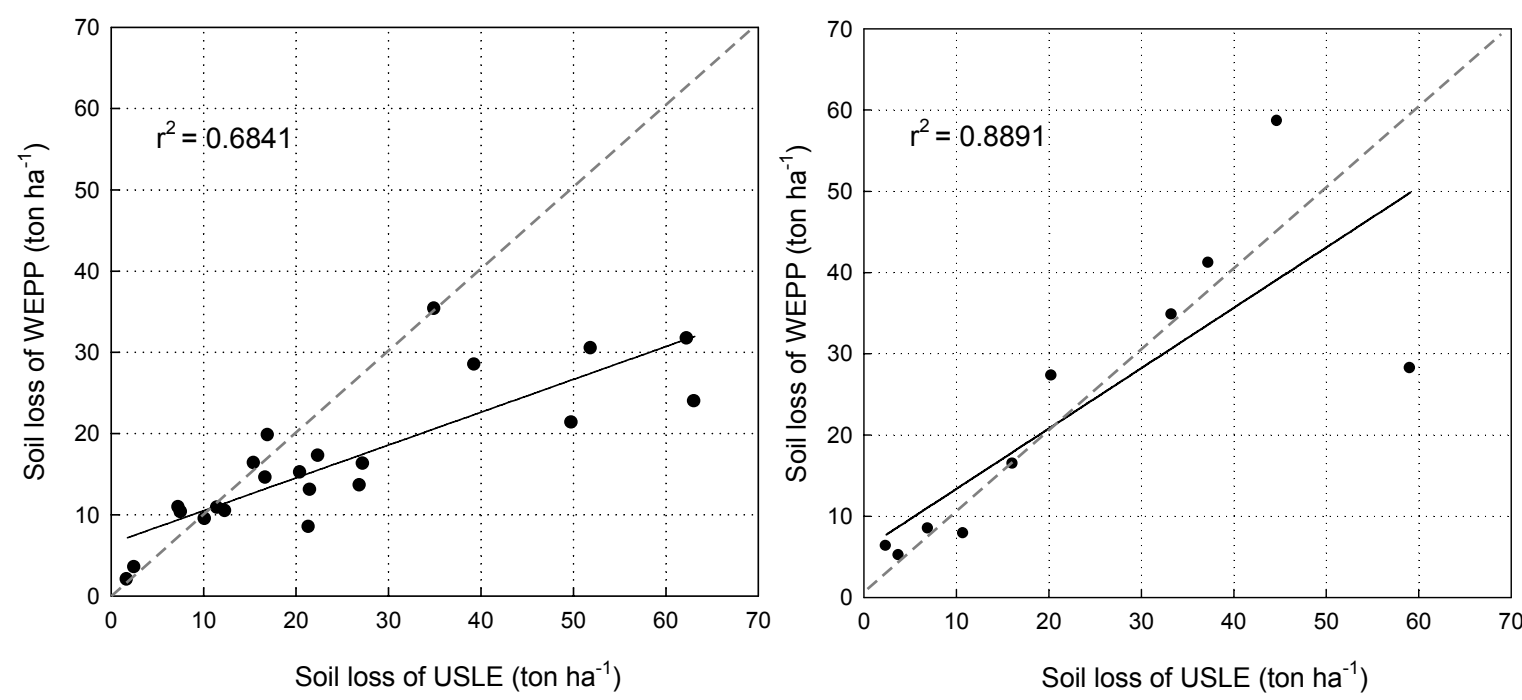

Fig. 3. Comparison of predicted average annual soil erosions using USLE and WEPP over study sites in Chuncheon (left) and Jeonju (right). 
model was based on database in US, so it is a biggest problem to use in Korea. Therefore, the demand to modify WEPP usable for Korea situations has been increased.

Based on author's knowledge, this is the first study that was carried out with the specific objective for calibration and evaluation of the WEPP model to estimate of runoff and sediment yield under Korea conditions by selecting a case study area. Main focus has been given to adopt and build/modify WEPP model suitable to quantify the results of erosion process in Korea situations. Two models, USLE and WEPP models, were applied and calibrated on agricultural fields in Chuncheon and Jeonju. As regard to computed values, in general, WEPP produces much delicate but smaller estimates than USLE. However, the findings show the promising results that WEPP could contribute to increase the accuracy of soil prediction.

\section{Acknowledgements}

This paper was supported by the Korean Research Foundation Grant funded by the Korean Government (MOEHRD) (KRF-2005-214-F00027).

\section{REFERENCES}

1. Clark, E.H., Haverkamp, J.A., Chapman, W. (1985) Eroding Soils. The off-farm Impacts, The Conservation Foundation, Washington, DC, USA, p.252.

2. Lal, R. (1995) Erosion-crop productivity relationships for soils of Africa. Soil Sci. Soc. Am., 59, 661-667.

3. Pimentel, D., Harvey, C., Resosudarmo, P., Sinclair, K., Kurz, D., McNair, M., Crist, S., Shpritz, L., Fitton, L., Saffouri, R., Blair, R. (1995) Environmental and economic costs of soil erosion and conservation benefits, Science, 267, 1117-1123.

4. Daily, G., Dasgupta, P., Bolin, B., Crosson, P., Guerny, J.du., Ehrlich, P., Folke, C., Jansson, A.M., Kautsky, N., Kimzig, Levin, S., Maler, K.G., Anderson, P.P., Siniscalo, D., Walker, B. (1998) Food production, population growth, and the environment, Science, 281, 1291-1292.

5. Matson, P.A., Parton, W.J., Power, A.G., Swift, M.J. (1997) Agricultural intensification and ecosystem pro perties. Science, 277, 504-509.

6. Amore, E., Modica, C., Nearing, M.A., Santoro, V.C. (2004) Scale effect in USLE and WEPP application for soil erosion computation from three Sicilian basins, J. Hydrol., 293, 100-114.

7. DiSilvio, G. (1996) Interrimento e riabilitazione degli invasi artificiali, L'acqua, 6, 49-54.

8. Rendchler, C.S. and Harbor, J. (2002) Soil erosion assessment tools from point to regional scales-the role of geomorphologists in land management research and implementation, Geomorphology, 47, 189-209.

9. Wischmeier, W.H. and Smith S.S. (1965) Predicting rainfall erosion losses from cropland east of the Rockey Mountains: Guide for selection of practices for soil and water conservation, U.S. Department of Agriculture, Agriculture Handbook, No. 282.

10. Flanagan, D.C., Gilley, J.E., Franti, T.G. (2007), Water Erosion Prediction Project (WEPP): Development history, model capabilities, and future enhancements, 50, 1603-1612.

11. Foster, G.R. and Lane, L.J. (1987) User requirements USDA-Water Erosion Prediction Project (WEPP), NSERL Report No. 1, USDA-Agricultural Research Service, NSERL, West Lafayette, Indiana 47907-2077, USA.

12. Nearing, M.A., Foster, G.R., Lane, L.J., Finkner, S.C. (1989) A process-based soil erosion model for USDA-Water Erosion Prediction Project technology, Trans. ASAE, 32, 1587-1593.

13. Flanagan, D.C. and Nearing, M.A. (1995) U.S. Department of Agriculture (USDA) Water Erosion Prediction Project (WEPP): Hillslope profile and watershed model documentation. National Soil Erosion Research Laboratory (NSERL) Report No. 10, USDA-Agricultural Research Service, NSERL, West Lafayette, Indiana 47907-2077, USA.

14. Ghidey, F. and Alberts, E.E. (1996) Comparison of measured and WEPP predicted runoff and soil loss for Midwest claypan soil. Trans. ASAE, 39, 1395-1402.

15. Wischmeier, W.H. and Smith S.S. (1978) Predicting rainfall erosion losses - a guide to conservation planning, U.S. Department of Agriculture, Agriculture Handbook, No. 537.

16. Park, J.H., Woo, H.S., Pyun, C.K., Kim, K.K. (2000) A 
study of distribution of rainfall erosivity in USLE/ RUSLE for estimation of soil loss. JKWRA, 33, 603-610.

17. Box. Jr.J.E. (1981) The effect of surface slaty fragment on soil erosion by water, Soil Sci. Soc. Am., 43, 111-116.

18. Laflen, J.M., Flanagan, D.C., Engel, B.A. (2004) Soil erosion and sediment yield prediction accuracy using WEPP, JAWEA, 40, 289-297.

19. Lindstrom, M.J., Schumscher, T.E., Lobb, D.A.,
Schumacher, J.A. (1999) Soil Erosion: a combined analysis of tillage and water erosion over a complex landscape, Proceeding of $10^{\text {th }}$ International Soil Conservation Organization Conference, West Lafayette, IN, USA.

20. Kim, M.K., Flanagan, D.C., J.R. Frankerberger, C.R. Meyer (2009) Impact of precipitation changes on runoff and soil erosion in Korea using CLIGEN and WEPP, J. of Soil and Water Conserv., (In press). 